Faculdade de Ciências Econômicas da UFRGS
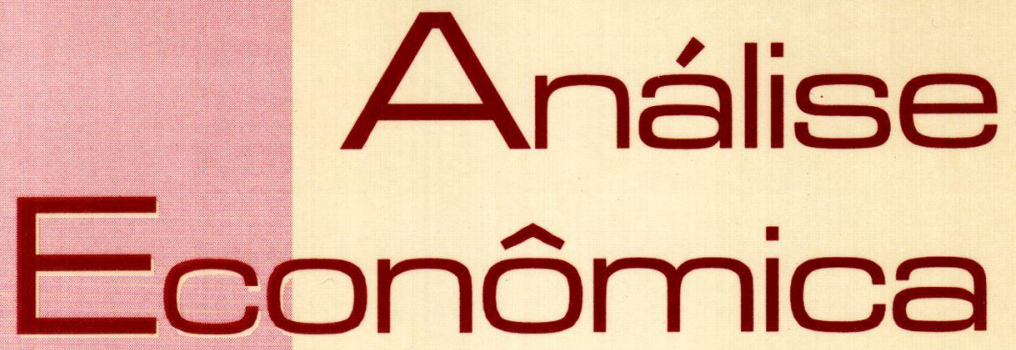

A Instabilidade Financeira dos Anos 90: Alqumas Implicações para as Economias Capitalistas Periféricas André Cunha e Daniela Prates

A Ampliação Recente da Participação Estrangeira no Sistema Bancário Brasileiro Maria Cristina Penido de Freitas

INFRA-ESTRUTURA dE INfORMAÇÕES E SISTEMA Nacional de InOvação

Eduardo da Motta e Albuquerque

Custo Social dos Recursos Hídricos em Bacias Hidrográlicas Internacionais: O Caso da Bacia do Paraná Jandir Ferrera de lima e José Carrera-Fernandez

Preferência pela liovidez e Escollha de Porrtólio

José Luis Oreiro

Eficiência, Objetivo e Coordenação da Política Macroeconômica no Período: 1974 - 1979

JoÃo Sicsú

Macroeconomia Moderna: Keynes e a ECONOMIA CONTEMPORÂNEA - Resenha

Simone Silva de Deos

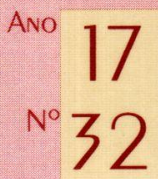


Universidade Federal do Rio Grande do Sul

Reitora: Proft. Wrana Maria Panizzi

Faculdade de Ciências Econômicas

Diretora: Prof ${ }^{a}$. Otilia Beatriz Kroeff Carrion

Centro de Estudos e Pesquisas Econômicas

Diretor: Prof. Fernando Ferrari Filho

Departamento de Ciencias Econômicas

Chefe: Prof Luiz Alberto Oliveira Ribeiro de Miranda

Curso de Pós-Graduação em Economia

Coordenador: Prof. Marcelo Savino Portugal

Curso de Pós-Graduaçāo em Economia Rural

Coordenador: Prof. Carlos Guilherme A. Mielitz Netto

Conselho edtrorial

Achyles B. Costa, Aray M. Feldens, Carlos A. Crusius, Carlos G. A. Mielitz Netto, Eduardo A. Maldonado Filho, Eduardo P. Ribeiro, Eugênio Lagemann, Fernando Ferrari Filho, Gentil Corazza, Marcelo S. Portugal, Nali J. Souza, Otilia B. K. Carrion, Paulo A. Spohr, Paulo D. Waquil, Pedro C. D. Fonseca, Roberto C. Moraes, Ronald Otto Hillbrecht, Stefano Florissi, Eleutério F. S. Prado (USP), Fernando H. Barbosa (FGV/RJ), Gustavo Franco (PUC/RJ), João R Sanson (UFSC), Joaquim P. Andrade (UnB), Juan H. Moldau (USP), Paul Davidson (Univ. of Tennessee), Werner Baer (Univ. of Illinois).

Comissão EDITORLAL

Eduardo Augusto Maldonado Filho, Fernando Ferrari Filho, Gentil Corazza, Marcelo Savino Portugal, Paulo Dabdab Waquil; Roberto Camps Moraes.

EDrTor: Gentil Corazza

Edrror Adjunto: Pedro Silveira Bandeira

SeCretaria: Laize Espindula.

REVISÃo DE TEXTos: Vanete Ricacheski.

Fundador: Prof. Antônio Carlos Santos Rosa

Os materiais publicados na revista Análise Econômica são da exclusiva responsabilidade dos autores. É permitida a reprodução total ou parcial dos trabalhos, desde que seja citada a fonte. Aceita-se permuta com revistas congêneres. Aceitam-se, também, livros para divulgação, elaboração de resenhas e recensões. Toda correspondência, material para publicação (vide normas na terceira capa), assinaturas e permutas devem ser dirigidos ao seguinte destinatário:

Prof, Gentul Corazza

Revista Análise Econômica - Av. João Pessoa, 52 CEP 90040-000 PORTO ALEGRE - RS, BRASIL

Telefones: 0xx (51) 316-3348 e 316-3440 - Fax: 0xx (51) 316-3990 rae@vortex.ufrgs.br

Análise Econômica

Ano 17, n. 32, setembro, 1999 - Porto Alegre

Faculdade de Ciências Econômicas, UFRGS, 1999

Periodicidade semestral, março e setembro.

ISSN 0102-9924

1. Teoria Econômica - Desenvolvimento Regional -

Economia Agrícola - Pesquisa Teórica e Aplicada -

Periódicos. I. Brasil.

Faculdade de Ciências Econômicas,

Universidade Federal do Rio Grande do Sul.

CDD 330.05

CDU 33 (81) (05) 


\title{
Eficiência, objetivo e coordenação da política macroeconômica no período 1974-79*
}

Jỗo Sicsǘ $\tilde{A}^{*}$

\begin{abstract}
Sinopse: Existe uma tese bastante influente que afirma que a política econômica implementada durante o período 1974-78 possuía objetivos irreconciliáveis: estabilização e crescimento. O ministro Mário Henrique Simonsen teria sido o defensor do primeiro objetivo e João Paulo dos Reis Velloso, à época, titular do Ministério do Planejamento, teria defendido exclusivamente a segunda meta. $O$ objetivo do artigo é mostrar que a tese existente acerca da política econômica implementada no período 1974-78 é incorreta. Mostra-se que a política econômica não estiolou-se e que possuía metas compatíveis.
\end{abstract}

Palavras-chave: Política Econômica 1974-78 - Coordenação de Políticas Macroeconômicas - Falsos Conflitos.

\begin{abstract}
There is an influential thesis about the economic policy of the Brazilian economy in the period 1974-78 which emphasizes that the economic policy had incompatible goals: stabilization and growth. Minister Mario Henrique Simonsen would have advocated the former and João Paulo dos Reis Velloso, Minister of Planning, would have supported exclusively the last one. The article's aim is to reveal that the influential thesis on this period is not correct. It stresses that the economic policy was powerful and it had compatible goals.
\end{abstract}

Key words: Economic Policy 1974-78 - Coodination of Macroeconomic Policies - False Conflicts.

\section{Introdução}

Existe uma tese bastante influente acerca da política econômica implementada no Brasil durante o período 1974-79. Essa tese enfatiza que a política econômica daquele período possuía objetivos incompatíveis e que utilizava os instrumentos monetários e fiscais de forma conflitante. Tem-se afirmado que nos anos 1974-79 existiam dois pólos opostos no interior do Governo representados pelo Ministério da Fazenda, cujo titular era Mario Henrique Simonsen, e pelo Ministério do Planejamento, cujo titular era João Paulo dos Reis Velloso. A oposição existiria em função dos desejos do primeiro de eliminar a inflação com métodos recessivos, enquanto o segundo visava impulsio-

\footnotetext{
"O autor agradece a leitura atenciosa e os comentários elogiosos feitos pelo professor A. Barros de Castro a uma versão preliminar do presente artigo. Contudo, valem as observações de praxe $O$ apoio da Faperj é também reconhecido.

** Professor adjunto do Departamento de Economia da Universidade Federal Fluminense (UFF).
} 
nar a economia rumo ao crescimento. Uma versão mais nítida da referida tese considera ainda que o árbitro dos conflitos seria o Presidente da República, o General Ernesto Geisel, e que tais conflitos predominantemente foram resolvidos a favor da opção pelo crescimento em detrimento da opção pela estabilização. Esse conjunto de idéias aparece de forma dispersa em textos variados e com argumentos diversos. Há de comum somente um sentimento cético em relação à política macroeconômica da gestão Simonsen-Velloso.

Coutinho afirmou que "entre 1974 e 1978 a política econômica estiolou-se na tentativa de conjugar objetivos irreconciliáveis" (1981, p. 77). Segundo esse autor, projetou-se um novo padrão de expansão que visava à manutenção das taxas de crescimento do período 1967.73 e, simultaneamente, objetivava-se a desaceleração da inflação e a contenção do déficit do balanço de pagamentos. Concluiu, portanto, que havia "uma contradição inequívoca entre a política de gasto e investimento público, ambiciosa e expansionista, e a política de crédito e financiamento que deveria seguir objetivos contencionistas" (1981, p. 77).

Carneiro (1990) afirmou que o Governo possuía uma equipe híbrida composta, no Planejamento, por técnicos que se caracterizaram por produzir projetos de impacto e, na Fazenda, a característica marcante era o conservadorismo cartesiano de Simonsen. E, como juiz das eventuais divergências sobre os rumos da economia, tinha-se "um Presidente sempre presente e pronto a presidir" (1990, p. 298). Carneiro afirmou ainda que os conflitos entre estabilização e ajuste estrutural marcaram a política econômica do Governo Geisel: "estabilizar a economia ou dar prioridade à continuidade do crescimento" (1990), essa era a questão que permaneceu durante o período $1974-79$ sem qualquer solução definitiva. Conseqüentemente, segundo Carneiro, o País optou por uma política econômica de caráter precário e inarticulado.

Roberto Campos afirmou que o " gabinete do presidente Geisel, disciplinado na aparência, ocultava graves clivagens. Simonsen, preocupado com o balanço de pagamentos, pregava contenção e austeridade. Reis Velloso, no Planejamento, ansiava por projetos desenvolvimentistas"(1998, p. 11). Segundo Campos, Simonsen se utilizava de relatórios confidenciais para pregar junto ao presidente a implementação de medidas restritivas. E, por ultimo, disse que o Ministro da Fazenda efetivamente "....aplicou intermitentemente medidas contracionistas que reduziram o crescimento..." (1998, p. 11).

Bresser Pereira (1983), embora muito menos cético que os outros, afirmou que, no período 1974-1979, o País teve uma política econômica marcada por uma contradição básica. O II PND levou o país a um grande esforço de investimento, que, segundo esse autor, conduziu ao endividamento externo, além de produzir pressões inflacionárias. Em sentido oposto, explicou Bresser Pereira, a partir do Ministério da Fazenda e do Banco Central, procurava-se 
combater a inflação através de políticas restritivas. Sua conclusão foi que no seio do próprio Governo existiam "uma posição desenvolvimentista e intervencionista, de um lado, e uma posição conservadora ou monetarista, de outro. A posição monetarista, entretanto, nunca foi radical e de qualquer forma jamais chegou a prevalecer inteiramente." (1983, p. 120-1).

O objetivo do artigo é mostrar que a tese-crítica acerca da política econômica implementada no período Simonsen-Velloso é insuficiente. Mostra-se que a política econômica não estiolou-se e que possuía metas compatíveis. Para alcançar o objetivo do artigo, define-se um método de avaliação da eficiência de políticas macroeconômicas que é exposto na seção 2 . Faz-se, na seção 3 , uma discussão acerca do objetivo da política econômica adotado no Governo Geisel. Na seção 4, analisa-se se houve conflitos entre as políticas monetária e fiscal àquele período. E, na seção 5 , discute-se que tipo de sinais os policymakers emitiam aos agentes durante os anos 1974-79. Na última seção, faz-se um sumário das principais conclusões do texto, dentre elas, que a política econômica do período em questão possuía metas congruentes e não utilizou de forma contraditória os instrumentos fiscais e monetários. Cabe ressaltar que o artigo está preocupado em discutir exclusivamente o binômio crescimento-inflação. Um outro-binômio, embora relevante à época, já teve sua discussão aprofundada na literatura, a saber, crescimento-desequilíbrio externo. ${ }^{1}$

\section{Critérios de eficiência de políticas macroeconômicas}

Faz-se necessário a definição de um método de avaliação sobre a eficiência de políticas macroeconômicas para que o objetivo do artigo seja alcançado. Sem definir com precisão um método de avaliação de ações econômicas governamentais, torna-se impossível tecer críticas contundentes a um determinado esquema de política econômica - tal como fizeram os críticos da gestão Simonsen-Velloso. Indefinições metodológicas são o motivo pelo qual as críticas apareceram de forma dispersa, excessivamente adjetivadas e com fundamentos nebulosos. Um processo de crítica mais rigoroso seria aquele que evidencia a distância entre um modelo de política econômica que pode ser considerado eficiente e aquele que foi efetivamente praticado no período 1974-79. Portanto é imprescindível a definição de critérios de avaliação de eficiência de políticas econômicas. Buscou-se construir tal método com base em algumas idéias do economista inglês John Maynard Keynes e de alguns dos seus seguidores.

Segundo a teoria da política econômica de J.Tinbergen (1952), o número de objetivos almejados deve ser inferior ao número de instrumentos que po-

\footnotetext{
${ }^{1}$ Uma discussão aprofundada sobre o binômio crescimento-desequilibrio externo pode ser encontrada em
} Castro \& Pires de Souza (1985) 
dem ser utilizados. Caso contrário, pelo menos um objetivo não seria alcançado se existir trade-off entre eles. Sendo assim, cada objetivo deve ter pelo menos um instrumento correspondente. Embora essa seja uma condição necessária não é suficiente para o sucesso de uma intervenção macroeconômica. A coordenação na utilização dos instrumentos torna-se fundamental quando um objetivo possui mais de um instrumento que pode ser acionado.

A coordenação da utilização de instrumentos de intervenção macroeconômica é fundamental. Quanto mais coordenados estiverem os instrumentos monetários entre si e esses, por sua vez, com os instrumentos fiscais, mais eficiente provavelmente será a política econômica. A coordenação é necessária porque, como afirmou Cairncross, "todos os instrumentos de política econômica interagem. O que ocorre quando se utiliza qualquer instrumento depende do estado dos demais instrumentos de política e das condições que prevalecem naquele momento." (1992, p. 198). Cada instrumento utiliza um canal de transmissão diferente agindo com timing e intensidades diversas, mas todos afetam uma única variável, a demanda. Logo, é imprescindível a coordenação da utilização das várias ferramentas que agem sobre o mesmo objeto, a demanda. ${ }^{2}$

Embora a coordenação da utilização dos instrumentos de política macroeconômica seja imprescindível, outros dois critérios devem ser observados para o julgamento sobre a eficiência de uma determinada ação macroeconômica. Uma política macroeconômica eficiente seria aquela que, além de criar o mínimo de utilização-contraditória entre seus instrumentos fiscais e monetários, persegue um objetivo não-ambíguo e, também, emite o máximo de sinais aos agentes a fim de estimulá-los a agir no mesmo sentido da direção apontada/adotada pelas autoridades.

Uma política econômica para ser eficiente deve emitir nítidos sinais aos agentes a fim de estimulá-los a agir no sentido da direção indicada pelos policymakers. Quanto mais nítidos forem os sinais de política, mais seguros e confiantes estarão os agentes para decidir, assim, maior será o estímulo privado para agir e menor será a intensidade e o tempo de utilização dos instrumen-

\footnotetext{
${ }^{2}$ A atenção de Keynes dada à necessidade de coordenação dos instrumentos de política monetária entre si e, simultaneamente, com os instrumentos de política fiscal foi expressa, por exemplo, no seu plano de busca do pleno emprego para a Inglaterra no período imediatamente anterior a Segunda Guerra Keynes sugeriu que: deveriam ser evitadas taxas de juros mais altas - a taxa de juros de longo termo não deveria exceder $2 \frac{1}{2} \% \mathrm{e}$ a taxa de juros bancária deveria ser mantida em torno de $2 \%$ a a ; uma política físcal de taxação seria a base para a obtenção de recursos reais por parte do Governo visando à compra de armamentos; através da emissão de papéis com maturidades diferenciadas, o Governo deveria permitir aos agentes manter a estrutura de maturidade de dívida pública desejada, assim, preferências poderiam ser exercidas e se evitaria de se ter de oferecer taxas de juros mais elevadas para compensar uma liquidez menor de um ativo-papel; as autoridades deveriam estar atentas para absorver a poupança (via emissão de dívida) gerada por um gasto do Governo, assim, pressões seriam evitadas sobre o mercado de bens e de ativos financeiros - logo, poderia ser preservada a estrutura de taxas de juros almejada. Essas medidas foram descritas por MOGGRIDGE (1993, p. 129).
} 
tos de política econômica que serão acionados pelas autoridades. Estas podem sinalizar aos agentes o provável contexto futuro porque são capazes de influir sobre a construção desse futuro - dado o volume de recursos que mobilizam e a notável influência sobre certas variáveis que possuem. Essa reconhecida capacidade de influência sobre a construção de contextos econômicos por parte das autoridades pode estimular os agentes a decidir de acordo com o esperado. Portanto os sinais emitidos pelas autoridades podem induzir a formação de expectativas auto-realizáveis: agentes acreditam que determinado contexto futuro ocorrerá, então, tomam decisões consistentes com suas expectativas, que terminam por ser validadas pela realidade - dado que os agentes agiram para construir aquele cenário esperado.

O critério da necessidade de emissão de nítidos sinais está rigorosamente de acordo com a concepção de planejamento econômico de Keynes. Para esse autor, o termo planejamento econômico possui um significado mais extenso que política econômica. $O$ primeiro, além de englobar o segundo, refere-se à realização de amplas transformações econômicas, tais como reformas institucionais. Planejamento e, conseqüentemente, políticas econômicas não são, para Keynes, formas de intervenção que significam: controle da economia, fim do princípio da liberdade ou imposição de decisões individuais. Pelo contrário, o planejamento econômico deve-se restringir a orientar a sociedade e direcionar (ou induzir) decisões privadas. ${ }^{3}$ Portanto a nitidez das intenções e do modo de ação das autoridades é necessária à indução de decisões/ações privadas. Segundo Tobin (1987, p. 8), Keynes tinha em mente algo semelhante ao planejamento francês do pós-guerra em que o Governo fomentou e coordenou a emissão de sinais de superação do pessimismo para incentivar decisões de investimento.

Como será mostrado a seguir (na seção 4), a política econômica do período 1974-79 foi uma política de stop-and-go. Contudo uma política de stopand-go, em princípio, não é necessariamente uma política ineficiente. Plagiando Friedman (1968) em um sentido que ele certamente não concordaria, podese afirmar que um carro (uma economia) tem freio e acelerador (instrumentos de política econômica). Cada um deve ser utilizado a seu tempo, de acordo com as circunstâncias. O sinal vermelho indica que é hora de desacelerar/freiar, o verde indica que é hora da partida. Um carro dirigido de forma ineficiente seria aquele que seu motorista, simultaneamente, apóia um pé no freio e o outro no acelerador. Assim, o automóvel não possuiria rumo definido: cami-

\footnotetext{
${ }^{3}$ Cairncross, percebendo essa importante característica dessas proposições intervencionistas, afirmou:

“...Keynes foi um apóstolo da direção econômica mais do que da planificação econômica” (1992, p.76). Alec Cairncross fez essa afirmativa se baseando no fato de que a planificação defendida por Keynes é do tipo indicativo. $O$ intervencionismo de Keynes não guarda qualquer semelhança com o planejamento de sentido compulsório adotado nas economias socialistas até o final da década de 1980
} 
nharia para frente ou permaneceria parado? Equivalentemente, essa situação caracterizaria uma política econômica sem objetivo definido. Ademais, a utilização-contraditória dos instrumentos de direção provocaria desgaste de combustível e das lonas de freio e emitiria sinais nebulosos aos pedestres que estariam atravessando sobre a faixa de segurança: atravessar ou permanecer aguardando? Analogamente, esse contexto caracterizaria uma política econômica com utilização-contraditória dos instrumentos fiscais e monetários e que estaria emitindo mais ruídos do que sinais claros da direção adotada.

Tendo sido definido um método de avaliação qualitativa de eficiência de políticas econômicas, utilizar-se-á tal método para avaliar a política implementada pela gestão Simonsen-Velloso. Na próxima seção será discutido se havia um objetivo prioritário de política econômica durante essa gestão. Na seção 4 , será feita uma avaliação das ações monetárias e fiscais, observando-se se houve utilização-contraditória dos instrumentos de política econômica. E, por último, analisar-se-á o tipo de sinal que tal política emitia aos agentes econômicos, especialmente, aos empresários. Assim, espera-se cumprir o objetivo do artigo que é caracterizar a política econômica desenvolvida naquele período de forma oposta à tese defendida, principalmente, por Coutinho (1981), Carneiro (1990) e Campos (1998).

\section{O objetivo da política econômica do governo Geisel}

O objetivo da política econômica do Governo Geisel era: crescer o $P I B$ sem acelerar a taxa de inflação. Embora esse objetivo não tenha sido explicitado nesses termos em nenhum documento oficial, as ações da equipe governamental apontavam nitidamente nessa direção. A economia deveria crescer até que o sinal vermelho da aceleração da taxa de inflação acendesse. Contidas as pressões inflacionárias, o crescimento econômico deveria retomar o seu curso original com sinal verde. Assim, o período em discussão foi marcado por uma política de stop-and-go. ${ }^{4} \mathrm{O}$ compromisso de João Paulo dos Reis Velloso com o crescimento da economia daquele tempo é inquestionável. Além do seu compromisso com as teses desenvolvimentistas, havia por parte do Ministro do Planejamento uma nítida preocupação com os demais problemas macroeconômicos, em especial, a inflação. E, pode-se afirmar que foi um erro crasso pensar que Simonsen, por ser considerado um monetarista, objetivava a eliminação da inflação com a utilização de métodos recessivos. Seu compromisso era, apenas e tão-somente, combater as tendências de aceleração da taxa de inflação e não a inflação propriamente dita.

\footnotetext{
${ }^{4}$ Reis Velloso recentemente admitiu que, a partir de meados da gestão que ele e Simonsen comandaram a economia brasileira, "o crescimento seria o maior possível, uma vez realizados [...] dois ajustes [o ajuste do balanço de pagamentos e o ajuste quanto à inflação]” (VELL.OSO, 1998, p. 19).
} 
Se Simonsen era um monetarista-conservador, como afirmavam os críticos da política econômica aplicada no período 1974-79, sua opção teórica era bastante coerente com a postura que adotou à frente do Ministério da Fazenda: combater unicamente o crescimento das taxas de inflação. $O$ monetarismo durante a década de 1970 era representado basicamente pelo pensamento friedmaniano. No modelo de Friedman, exposto no seu conhecido artigo The Role of Monetary Policy, taxas de inflação (inclusive elevadas) constantes não provocam qualquer perturbação econômica. Perturbações ocorrem quando a inflação não é antecipada, o que geralmente significa uma taxa crescente de inflação (Friedman, 1968). A inflação constante seria neutra na concepção de Friedman. No seu modelo, taxas de inflação constantes dariam aos agentes plena capacidade de previsão e, assim, sob tais condições, as decisões individuais tornar-se-iam consistentes com as curvas de preferências reais entre lazer e trabalho.

O Ministro da Fazenda, supostamente simpatizante do monetarismo, estava imbuído da idéia de que seu papel no Governo era combater a inflação crescente. Simonsen, em palestra proferida à Comissão de Economia da Câmara dos Deputados, no início do ano de 1976, afirmou que um dos problemas econômicos era a "manutenção da inflação sob adequado controle" (1976a, p. 1). Em julho de 1976, em outra palestra, desta vez proferida na ESG (Escola Superior de Guerra) declarou que um dos problemas a solucionar era "a redução do ritmo inflacionário"(1976b, p. 1). No ano seguinte, em palestra aos empresários disse: “...a política monetária, embora não seja o único, representa um poderoso instrumento de regulagem da inflação...”(1977, p. 1). Efetivamente, esse era o objetivo do Ministério da Fazenda: manter a inflação sob controle, regular a inflação, reduzir o seu ritmo de crescimento e não debelá-la em definitivo.

Simonsen, embora supostamente simpatizasse com o monetarismo, estava compromissado também com as políticas de fomento ao crescimento. $\mathrm{O}$ Ministro da Fazenda, em palestra proferida à Comissão de Economia da Câmara dos Deputados, afirmou ainda que "...se pensarmos apenas em combate a inflação, chegaremos a maus resultados em crescimento [...] e se nos concentrarmos apenas no crescimento a curto prazo [...] prepararemos um futuro suicídio inflacionário [...]" (1976a, p. 2). As palavras de Simonsen ao finalizar essa conferência são esclarecedoras sobre o objetivo da política econômica adotada pelo Governo: "[nosso objetivo] não comporta especulações pessimistas quanto à eventualidade de recessão, ou crescimento zero, crise cambial ou explosão inflacionária. Deveremos continuar crescendo a taxas significativas, com visível redução do déficit comercial e com a inflaçâo sob controle". (Simonsen, 1976a, p. 25-6). Simonsen denominou o objetivo da política eco- 
nômica do período Geisel de solução de compromisso satisfatória. Na palestra da ESG, explicou com mais detalhes tal denominação:

...quando temos vários objetivos a alcançar, não se pode esperar o ideal em cada um deles, mas apenas uma inevitável fórmula de compromisso. A formulação de política econômica, por sua vez, tornou-se bem mais complexa a partir de 1973 para países importadores de petróleo. De alguma forma parece que estamos diante de uma situação em que há mais equações do que incógnitas, o que podemos obter não é uma solução precisa para cada uma delas, mas a melhor aproximação possível para seu conjunto. $(1976 b$, p. 3).

Ainda na palestra da ESG, Simonsen mostrou, mais uma vez, que, embora sua tarefa no Governo fosse combater a aceleração da inflação, estava comprometido com as idéias desenvolvimentistas, seu raciocínio era o seguinte:

Suponhamos [...] que pensemos apenas em combater a inflação. A melhor receita, no caso, seria a do máximo aperto na política monetária e fiscal, do congelamento de salários, taxas de câmbio e vários preços administrados pelo Governo e do amplo corte de investimentos. Esse unilateralismo, todavia, prejudicaria o crescimento presente pelo excessivo aperto monetário e fiscal; [e] o crescimento futuro pelo corte de investimentos...(1976b, p. 3)

Carneiro afirmou que "...o discurso em favor de um ajuste contracionista, então adotado na área do Ministério da Fazenda, parece ter sido antes motivado pela perda de controle monetário e pela repressão de preços ocorridas no final do governo anterior, do que por qualquer percepção explícita da necessidade de crescer menos...”(1990, p. 298). Essa afïrmação de Carneiro, embora apareça entre os seus argumentos céticos à política econômica implementada pela gestão Simonsen-Velloso, é plenamente adequada à tese oposta - defendida nesse artigo. Pode-se, então, afirmar que Simonsen visava, com seu discurso de tom contencionista, apenas à retomada do controle monetário e não, efetivamente, provocar uma recessão (ou uma desaceleração) para debelar a inflação. Nesse sentido, pode-se concluir que o Ministério da Fazenda também estava, verdadeiramente, compromissado com a meta de crescimento econômico.

Carneiro aduziu ainda que "um certo otimismo pela existência de indexação contribuía para aumentar a tolerância com taxas mais elevadas de inflação" (1990, p. 299). Essa afirmativa também reforça a idéia de que Simonsen não estava compromissado com o fim da inflação. Contudo tal otimismo, destacado por Carneiro, era emanado pelo principal teórico do monetarismo à época. Em artigo pouco conhecido, chamado Monetary Correction de 1974, Friedman defendeu a neutralidade da inflação em um con- 
texto de plena indexação de preços e salários. Nesse texto, Friedman se opôs às regras de reajuste que buscavam embutir nos preços e salários a inflação futura esperada: a regra ideal que neutralizaria os efeitos da inflação seria aquela que incorporaria somente a inflação passada integralmente. Portanto, nesse aspecto, Simonsen estava completamente alinhado com o receituário monetarista existente àquela época. São suas as seguintes palavras: “... é verdade que os efeitos econômicos da inflação são bem menos nocivos no Brasil do que em outros países, devido ao instituto da correção monetária. Distorções classicamente associadas à alta crônica dos preços, como o desestímulo à poupança, não se verificam no Brasil, graças a este instituto." (1976b, p.2).

Como conseqüência das idéias até aqui expostas, admite-se que Simonsen, no que diz respeito exclusivamente à administração monetária, podia ser considerado um simpatizante das idéias monetaristas de Milton Friedman - tal postura, o fez combater a inflaçâo crescente e conviver com a inflação estável dado que a economia brasileira já era bastante indexada. Contudo a aceitação em participar de um Governo abertamente intervencionista e desenvolvimentista indica uma postura mais ampla e eclética do que um monetarismo-puro. Simonsen participou de um Governo que fez a economia caminhar em marcha forçada devido às restrições externas; e isto estava em desacordo direto com as proposições monetaristas, mais gerais, de não-intervencionismo. Então, podese concluir que Simonsen era friedmaniano em relação à gestão monetária e um policymaker keynesiano acerca das opções fiscais do Governo. Equivalentemente, Simonsen não era um monetarista radical, nem um keynesiano míope às pressões inflacionárias. Essa caracterização é totalmente coerente com as palavras do próprio Ministro da Fazenda que, à época do Governo Geisel, afirmou: "mantemo-nos numa prudente equidistância entre friedmanianos extremados, que só acreditam na moeda, e os keynesianos que mal leram a Teoria Geral de Keynes..." (Simonsen, 1977, p. 1).

Essa seção objetivou mostrar quase que exclusivamente que Simonsen estava disposto a combater unicamente as taxas de aceleração inflacionária e não derrubar a inflação se utilizando de métodos recessivos. Contudo, embora essa não fosse a sua tarefa, estava também comprometido com o crescimento econômico. Portanto suas atitudes e decisões eram coerentes com a meta governamental de crescer sem aceitar variações positivas da taxa de inflação. Os objetivos do Governo somente seriam, como Coutinho (1981) chamou, irreconciliáveis se o Ministério do Planejamento hasteasse a bandeira do crescimento econômico, enquanto o Ministério da Fazenda hasteasse a bandeira do fim da inflação com recessão. João Paulo dos Reis Velloso e Mario Henrique Simonsen assumiram posturas adequadas ao objetivo governamental. ${ }^{5}$ Os dois

\footnotetext{
${ }^{5}$ Na próxima seção, será mostrado que o Ministro do Planejamento, Reis Velloso, estava compromissado não só com o objetivo do crescimento, mas também com o controle da inflação.
} 
ministros assinaram, por exemplo, a seguinte exposição de motivos ao Presidente da República em 24-04-1974: "o governo já definiu como prioridade número um da estratégia econômica manter as altas taxas de crescimento do produto real [...] Afirmou-se por outro lado a determinação de manter sob controle a inflação dentro de tratamento gradualista, consistente com a meta de crescimento." (O Globo, 25-04-1974).

Não se concluiu, entretanto, que não existiam divergências em pontos particulares. Segundo Velloso, existiam “... diferenças em pontos específicos, e até mesmo diferença de ênfase [...] Mas a orientação geral de política, assim como inflexões e correções de rumos, sempre foram definidos em conjunto, pelos dois ministros...” (1986, p. 301). Nesse sentido, pode-se concluir que a política econômica perseguia um objetivo único: crescer sem acelerar a taxa de inflação. Logo, nesse aspecto, a política implementada pode ser considerada eficiente. Uma política ineficiente seria aquela que possuísse objetivos ambíguos e/ou contraditórios, por exemplo, crescer e eliminar a inflação com métodos recessivos.

\section{Política contraditória ?}

Em seu artigo sobre a política econômica dos anos 1970, Bresser Pereira (1983) intitulou a seção que se refere ao período Simonsen-Velloso de Política Contraditória. E afirmou:

Na verdade, no período 1974-79, tivemos uma política econômica marcada por uma contradição básica. De um lado o Il PND definido pela presidência da República levava o país a um grande esforço de desenvolvimento, de caráter afinal anticíclico, que conduzia ao endividamento externo, além de produzir pressões inflacionárias. De outro lado, a partir do Ministério da Fazenda e do Banco Central procurava-se conter os dois processos através de políticas restritivas, as quais, entretanto, tinham duração relativamente curta.(1983, p. 120).

Seguindo os critérios definidos na seção 2, políticas podem ser caracterizadas como contraditórias (ou ineficientes) quando existe utilização-conflitante dos instrumentos monetários e fiscais. Essa seção objetiva avaliar em que medida houve utilização-contraditória dos instrumentos de política econômica no período 1974-79. Foram organizadas as tabelas 1, 2, 3, 4 e 5 que descrevem as ações monetárias e fiscais do Governo no período março de 1978 a fevereiro de $1979 .{ }^{6}$ Utilizou-se a variação percentual real do volume monetário de títulos governamentais vendidos ao público como uma proxy das necessidades de financiamento do déficit

\footnotetext{
${ }^{6}$ Essa é uma aproximação, porque a gestão do presidente Geisel foi de 15-03-1978 a 14-03-1979
} 
do Governo, portanto tal variação pode ser considerada representativa das ações de política fiscal adotadas. A variação percentual real dos meios de pagamentos foi considerada uma proxy adequada da política monetária adotada. Ambas as quantidades, meios de pagamento e títulos vendidos ao público, foram deflacionadas pelos valores das Obrigações Reajustáveis do Tesouro Nacional (ORTN).

As políticas monetária e fiscal foram classificadas, nas referidas tabelas,

Tabela 1: Primeiro Ano de Governo

\begin{tabular}{|c|c|c|}
\hline Trimestres & Política Monetária & Política Fiscal \\
\hline & Expansionista & Neutra \\
mar/74-mai/74 & $2 \%$ & $(1 \%)$ \\
\hline jun/74-ago/74 & Contracionista & Expansionista \\
& $(2 \%)$ & $14 \%$ \\
\hline set/74-nov/74 & Expansionista & expansionista \\
\hline dez/74-fev/75 & $9 \%$ & Neutra \\
& Contracionista & $0 \%$ \\
\hline
\end{tabular}

Tabela 2: Segundo Ano de Governo

\begin{tabular}{|c|c|c|}
\hline T'rimestres & Política Monetária & Política Fiscal \\
\hline mar/75-mai/75 & Expansionista & Expansionista \\
& $6 \%$ & $12 \%$ \\
\hline jun/75-ago/75 & Expansionista & Neutra \\
\hline set $/ 75-$ nov $/ 75$ & $12 \%$ & $0 \%$ \\
\hline & Expansionista & expansionista \\
dez $/ 75-\mathrm{fev} / 76$ & $6 \%$ & $15 \%$ \\
\hline
\end{tabular}

Tabela 3: Terceiro Ano de Governo

\begin{tabular}{|c|c|c|}
\hline T'rimestres & Política Monetária & Política Fiscal \\
\hline mar/76-mai/76 & expansionista & Contracionista \\
& $2 \%$ & $(2 \%)$ \\
\hline $\mathrm{Jun} / 76-\mathrm{ago} / 76$ & Neutra & $1 \%$ \\
\hline Set $/ 76-$ nov $/ 76$ & $0 \%$ & Neutra \\
\hline dez/76-fev $/ 77$ & Expansionista & $0 \%$ \\
\hline & $2 \%$ & Neutra \\
\hline
\end{tabular}


Tabela 4: Quarto Ano de Governo

\begin{tabular}{|c|c|c|}
\hline Trimestres & Política Monetária & Política Fiscal \\
\hline mar/77-mai/77 & expansionista & Neutra \\
& $4 \%$ & Expansionista \\
& Neutra & $4 \%$ \\
\hline Jun/77-ago/77 & $(1 \%)$ & Neutra \\
Set/77-nov/77 & Expansionista & Expansionista \\
\hline dez $/ 77-\mathrm{fev} / 78$ & $5 \%$ & $5 \%$ \\
\hline
\end{tabular}

Tabela 5: Quinto Ano de Governo

\begin{tabular}{|c|c|c|}
\hline Trimestres & Política Monetária & Política Fiscal \\
\hline mar/78-mai/78 & Neutra & expansionista \\
& $1 \%$ & $16 \%$ \\
\hline Jun/78-ago/78 & Neutra & Expansionista \\
& $1 \%$ & $3 \%$ \\
\hline Set/78-nov/78 & Expansionista & Expansionista \\
\hline dez/78-fev/79 & $4 \%$ & $2 \%$ \\
\hline
\end{tabular}

de acordo com a variação das magnitudes representativas (meios de pagamento e volume de títulos vendidos ao público, respectivamente), como: contracionistas, expansionistas ou neutras. Variações iguais ou inferiores a $1 \%$, negativas ou positivas, foram consideradas neutras. Estabelecer um limite, neste caso $1 \%$, é um ato subjetivo e inevitavelmente contaminado com algum grau de arbitrariedade. Entretanto esta foi a forma encontrada para se atenuar o efeito de possíveis imprecisões dos cálculos que, embora de reduzida magnitude, poderiam eventualmente distorcer os resultados qualitativos indicados pela análise seqüencial dos dados. Em cada tabela, abaixo da classificação das políticas econômicas, aparece a variação percentual em relação ao trimestre anterior. Todos os dados utilizados para a elaboração das tabelas foram fornecidos pela ANDIMA.

As tabelas 1, 2, 3, 4 e 5 não indicam nenhuma seqüência de períodos em que a política monetária tenha persistentemente sido acionada em um sentido enquanto a política fiscal foi insistentemente acionada em sentido contrário. Somente dois trimestres isolados, durante todo o período de Governo, com uma política fiscal expansionista e uma política monetária contracionista (ou vice-versa) podem ser encontrados nas referidas tabelas. É o caso do segundo trimestre do primeiro ano de Governo e do primeiro trimestre do terceiro ano. 
Entretanto trimestres isolados com políticas acionadas em sentidos opostos não caracterizam uma utilização-contraditória dos instrumentos fiscais e monetários - o que caracterizaria tal utilização não-coordenada seria a continuidade, uma sequiência de trimestres.

Pontos isolados de utilização-contraditória dos instrumentos de política econômica não caracterizam uma política ineficiente. Pontos isolados de utilização-contraditória podem ocorrer em função do timing dos instrumentos. A política de gastos governamentais tem, por vezes, uso limitado para enfrentar problemas conjunturais porque esbarra em graves dificuldades técnicas (de edificações) e, às vezes, políticas. Por exemplo, programas de obras públicas somente podem ser ativados ou desativados de acordo com um cronograma de engenharia. Tal restrição implica uma menor flexibilidade desse instrumento. Por outro lado, os instrumentos de controle da liquidez da economia são mais flexíveis. São instrumentos que podem ser utilizados sob o comando exclusivo dos policymakers - instrumentos de controle monetário possuem um alto grau de discricionariedade. Portanto, dado o timing diferenciado de uso dos instrumentos de política econômica, a caracterização da utilização-contraditória somente pode ser feita quando identifica-se uma seqüência de pontos (no caso, trimestres) em que a política monetária foi ativada persistentemente em um sentido enquanto a política fiscal insistentemente foi acionada em sentido oposto - alguns pontos isolados não podem caracterizar a utilização contraditória de instrumentos porque podem ter sido configurados em razão de critérios nãoeconômicos (isto é, critérios técnicos de engenharia, por exemplo).

O objetivo do Governo Geisel era fazer a economia crescer sem acelerar a taxa de inflação. Nesse sentido, as políticas macroeconômicas deveriam servir a essa meta. As políticas fiscal e monetária deveriam ser expansionistas para estimular e apoiar o crescimento; e restritivas quando o Governo considerasse que as taxas de inflação eram ascendentes. Portanto duas questões devem ser definidas. Primeiro, a taxa de inflação aceitável pelo Governo: qual taxa acendia o sinal vermelho? $\mathrm{E}$, em segundo lugar, deve-se analisar se as políticas adotadas eram coerentes entre si e com o objetivo governamental.

O presidente Geisel assumiu o Governo, em março de 1974, diante de uma conjuntura que indicava claros sinais de aceleração da taxa de inflação. As taxas inflacionárias de janeiro e fevereiro, daquele ano, respectivamente registraram $2,93 \%$ e $2,68 \%$ (essas taxas foram calculadas com base no IGPDI, assim como todas as taxas apresentadas doravante). Em março, a taxa atingiu $4,5 \%$, em abril, $5,11 \%$ e, em maio, $3,52 \%$. Dado o quadro conjuntural, o Governo adotou medidas monetárias contracionistas já no segundo trimestre

${ }^{7}$ O Governo evitou explicitar metas quantitativas, a razão segundo VELLOSO (1986, p. 295) era que a equipe econômica não desejava criar compromissos com taxas específicas porque desejava manter uma maior margem de manobra para suas ações. 
do primeiro ano de Governo, que vai de junho a agosto de 1974, e iniciou uma redução do ritmo de expansão dos gastos públicos até o último trimestre desse primeiro ano - tal como é mostrado na tabela 1 . O resultado foi positivo, a inflação caiu para menos de $2 \%$ no terceiro trimestre de Governo (setembro a novembro de 1974). Assim, a política monetária voltou a ser expansionista ainda no terceiro trimestre. Provavelmente, em razão desse expansionismo monetário, a inflação do último trimestre do primeiro ano de Governo superou mais uma vez o patamar de $2 \%$, conseqüentemente, a política monetária ainda nesse período tornou-se contracionista novamente. $O$ resultado foi a queda da inflação para menos de $2 \%$ nos meses de março e abril de 1975 e o PIB crescera $9,8 \%$ em 1974.

Tudo indica que a taxa de inflação aceitável pela equipe econômica era de $2 \%$ ao mês - quando esse limite era ultrapassado, acendia-se o sinal vermelho. Tal conclusão é reforçada pela matéria do O Globo, de 15-03-1975, destinada a fazer um balanço do primeiro ano da administração Geisel. O referido jornal noticiou: "a inflação apresenta tendência declinante e, segundo os técnicos [do Governo], deverá estabilizar-se ao nível de $2 \%$ ao mês". Havia uma revelação implícita na matéria do periódico que indicava a aceitação dessa taxa de $2 \%$ por parte da equipe econômica. Como assinalado anteriormente, em março de 1975, a taxa de inflação foi de $1,58 \% \mathrm{e}$, em abril, 1,77\%. Esses resultados indicavam ao Governo a adoção de políticas expansionistas - apagou-se o sinal vermelho e acendeu-se o verde. Tais políticas foram implementadas durante todo o segundo ano de Governo (que vai de março de 1975 a fevereiro de 1976 - como é mostrado na tabela 2). Contudo, Coutinho (1981) atribuiu essa mudança de rota das políticas a fatores exógenos à estratégia econômica traçada pelo Governo, afirmou: "as pressões anti-recessionistas provocaram, a partir de meados de 1975, a reversão no sentido expansionista" (1981, p. 76-77). Carneiro (1990) também não atribuiu essa mudança de rumo a um plano de Governo que orientava as decisões dos policymakers. Afirmou:

Para a política econômica de curto prazo, a derrota do Governo nas urnas [em novembro de 1974] transformou 1975 em ano de recuo na tentativa de contenção de demanda. [...] A natural insatisfação interna no seio da burocracia do Estado gerada pelas tentativas de controle sobre os gastos públicos somou-se ao clima de desconforto causado pela instabilização inflacionária e pelo descontentamento empresarial em decorrência do controle dos preços industriais, fortalecendo-se assim junto ao Palácio do Planalto a corrente dos que defendiam a preservação do crescimento a qualquer custo.(1990, p. 303).

A inflação no ano de 1975 estabilizou-se em torno de uma taxa ligeiramente superior a $2 \%$ ao mês e o PIB cresceu 5,6\%. Somente a partir de dezem- 
bro de 1975 e janeiro e fevereiro do ano seguinte que a política fiscal reduziu o ritmo de gastos governamentais e a política monetária reduziu ligeiramente a liquidez da economia. Afinal, a inflação havia ultrapassado a média do ano de 1975 e atingira $3,09 \%$, em janeiro, e 4,16\%, em fevereiro de 1976 . O sinal vermelho havia acendido. De acordo com a estratégia governamental, era hora de mudar a rota das políticas monetária e fiscal. Entretanto, Coutinho afirmou, novamente e equivocadamente, que o motivo da mudança adotada foi uma rápida modificação na "configuração de forças dentro do Governo com o fortalecimento progressivo do setor responsável pela política de financiamento e crédito (min. Simonsen, M.F.-B.B.-CMN)" (1981, p. 79). Contrariamente, Reis Velloso disse recentemente que é "...importante ressaltar que tal dificuldade de sintonia fina era inerente à estratégia econômica, devendo ser resolvida dentro do mecanismo de coordenação do governo. E, pois, não resultava de conflito de posições entre a área da Fazenda e do Planejamento." (Velloso, 1998, p. 17).

Até novembro de 1976, a economia foi administrada com políticas monetárias ligeiramente expansionistas - o que pode ser observado na tabela 3 . $O$ resultado em termos de crescimento do PIB pode ser considerado um sucesso, houve uma variação positiva dessa variável da ordem de $9,7 \%$. No front da inflação, a batalha obteve êxito relativo. Por um lado, impediu-se uma aceleração explosiva das taxas inflacionárias, entretanto a inflação estacionou até setembro em novo patamar, entre 3 e $4 \%$ ao mês. O salto de patamar da inflação era o simples resultado de que o trade-off de curto prazo entre inflação e crescimento era uma das características daquele período econômico.(1986, p. 334) Esse novo patamar, contudo, com toda certeza não era aceito com tranquiilidade pelo Governo. Em discurso na Escola Naval, em 22 de outubro de 1976, o ministro Reis Velloso falou da necessidade de se reduzir a inflação "a uma taxa mensal de 2\%" (citado em Carneiro, 1990, p. 307). De acordo com o receituário estabelecido, houve uma contração monetária conjugada com uma política neutra de gastos públicos no último trimestre do terceiro ano de Governo. Segundo VELLOSO, "em agosto [de 1976], consoante orientação do Presidente, o Planalto expediu normas aos ministérios para que procedessem à revisão de seus programas de investimento. Em setembro, o Conselho Monetário apertou o crédito" (1986, p. 302). O resultado foi uma queda da inflação para um patamar ligeiramente superior a $2 \%$ ao final do ano de 1976.

No quarto ano de Governo, que vai de março de 1977 a fevereiro de 1978, o expansionismo fiscal foi conjugado com ações neutras da política monetária (e vice-versa) - tal como é mostrado na tabela 4. Portanto, predominou nesse período expansões de uma política conjugadas com reduções do ritmo de expansão da outra. Os resultados decorrentes da implementação des- 
sa política, que pode ser considerada cautelosa, foram: a inflação foi mantida sob controle num patamar ligeiramente superior a $2 \%$ nos últimos meses do ano de 1977, e o PIB cresceu modestamente para os padrões da época, $5,4 \%$ no ano.

No início do último ano de Governo, com inflação em um patamar ligeiramente superior a $3 \%$, a política monetária foi neutra e a política fiscal foi bastante agressiva (como mostra a tabela 5). Paralelamente à implementação dessas políticas, as taxas inflacionárias apresentaram brandos sinais de desaceleração, embora o Governo tivesse mantido o ritmo expansionista. No primeiro semestre do ano de 1978 , as taxas inflacionárias se mantiveram no mesmo patamar (superior a 3\%), o sinal vermelho acendeu. Houve uma drástica redução do ritmo de expansão dos gastos públicos que ocorreu durante os meses de junho, julho e agosto que, provavelmente, foi a responsável pela queda da inflação para um patamar inferior a $3 \%$ ao mês no segundo semestre de 1978. Contudo a política monetária permaneceu expandindo a liquidez da economia. Os resultados do ano de 1978 foram: o PIB cresceu 4,8\% e a inflação foi em média de aproximadamente $3 \%$ ao mês. No último trimestre de Governo (dezembro de 1978 e janeiro e fevereiro de 1979), uma nova expansão de gastos públicos aliado aos efeitos da política monetária de aumento da liquidez da economia, possivelmente, favoreceram uma nova escalada da inflação nos meses de janeiro, fevereiro e março de 1979 - quando a inflação superou $5 \%$ nesse último mês. Nesse sentido, cabe observar que este foi o único período que a estratégia econômica de promover políticas expansionistas somente com sinal verde (isto é, com uma taxa de inflação estacionada em torno de $2 \%$ ) não foi rigorosamente respeitada. Pode-se notar, nesse período, a aceitação de um novo patamar de inflação, em torno de $3 \%$ ao mês, por parte das autoridades econômicas do Governo.

Conclui-se, portanto, que não houve utilização-contraditória dos instrumentos de política monetária e fiscal durante a gestão Simonsen-Velloso e que a estratégia de política econômica foi basicamente respeitada - com exceção do último ano de Governo. Houve um plano de ação que norteou as decisões dos policymakers. Conseqüentemente, as ações de política econômica não podem ser atribuídas exclusivamente a disputas entre forças internas do Governo e nem a pressões externas - como fazem os críticos das políticas econômicas do período 1974-79. As políticas eram expansionistas visando ao crescimento do PIB e contracionistas (ou reduziam drasticamente o ritmo de expansão) quando havia perigo de perda de controle da inflação. Portanto a política econômica adotada não foi contraditória no que diz respeito à utilização dos seus instrumentos nem contraditória em relação aos objetivos almejados. 


\section{Os sinais da política macroeconômica e as decisões empresariais}

Uma política econômica eficiente seria aquela que, além dos critérios já discutidos, emite claros sinais aos agentes a fim de estimulá-los a agir - com menor incerteza em relação ao futuro - no mesmo sentido das ações governamentais. Quanto mais nítidos são esses sinais, maior será o estímulo privado e menor será a intensidade e o tempo de utilização dos instrumentos fiscais e monetários que serão acionados. Os responsáveis pela condução da economia durante o Governo Geisel, através de suas declarações públicas e ações de política econômica, transmitiram sinais de confiança ao empresariado estimulando-o a tomar decisões consistentes com a meta governamental.

O desequilíbrio das contas externas marcou o quadro econômico do ano de 1974. Apesar do volumoso crescimento das exportações naquele ano, uma elevação considerável dos preços das matérias-primas importadas causou o enorme déficit comercial. A opção convencional-ortodoxa diante desse quadro teria sido o ajustamento da economia, através de políticas fiscais e monetárias, restritivas às novas condições internacionais. Em oposição ao caminho convencional, o Governo optou pelo endividamento externo para crescer e gerar profundas reformas estruturais na economia. A opção não foi pelo ajustamento-adaptativo, mas sim pelo crescimento-transformador. Nesse sentido, o Governo anunciou aos agentes o seu Plano Nacional de Desenvolvimento (o II PND) cuja meta-principal era a "consolidação de uma economia moderna, mediante a implantação de novos setores, e a criação e adaptação de tecnologias".

O objetivo da política econômica do Governo Geisel - crescer sem acelerar a taxa de inflação - deve, portanto, ser qualificado. O crescimento almejado representava, ao mesmo tempo, continuidade e rompimento em relação ao período 1967-73. Continuidade em virtude da manutenção da meta de crescimento (apesar das condições adversas) e rompimento em razão dos setores considerados prioritários para liderar a nova onda de expansão. A liderança no período 1967-73 foi dos bens de consumo duráveis. No período Geisel, os setores considerados líderes seriam os produtores de insumos básicos e de bens de capital. Portanto a opção não foi pelo simples endividamento, mas sim pelo crescimento-com-endividamento visando a uma mudança estrutural da economia brasileira.

Segundo CASTRO (1985, p. 30), o Plano deixava claro aos agentes que a consecução das mudanças exigiria uma ativa presença do Estado na economia. Em entrevista à revista Visão de 19-04-1976, o Ministro Reis Velloso afirmou: "se você quiser atuar inteiramente pelo sistema de mercado, nas con- 
dições atuais da economia brasileira [...] não vai ter o setor privado atuando em siderurgia, em fertilizantes, em petroquímica em metais não-ferrosos etc." (citada em Castro, 1985, p. 32). Portanto o Governo deveria incentivar os empresários desses setores a tomar decisões consistentes com o objetivo da política econômica. Nas palavras de Castro, o Governo deveria "provocar decisões relevantes para a reorientação do processo de crescimento" (1985, p.35 grifou-se o original). Contudo tal reorientação não deveria implicar o abandono da safra de investimentos que foi iniciada no período 1967-73 e que estava em curso. Caso se permitisse que essa safra não fosse colhida comprometeria-se o estado expectacional dos empresários dificultando a adesão a um novo programa de investimentos. Naquele momento, a eficiência da política econômica implementada dependia de que os animal spirits dos capitalistas não esmorecessem.

O conjunto de investimentos desejados pelo II PND visava a uma mudança estrutural e, simultaneamente, o Plano objetivava sustentar as decisões empresariais de investimento para impedir que fosse criado um estado de expectativas desfavorável às reformas. Nesse sentido, o Governo não somente sinalizou, mas implementou uma série de estímulos capazes de engajar os empresários na nova onda de investimentos. Segundo Velloso, para que o empresário, principalmente o nacional, se engajasse em grandes projetos de investimento em áreas pesadas, [...] a solução foi orientar todo o sistema de incentivos do Governo para esses setores, considerados da mais alta prioridade, jogar toda a constelação de instrumentos do BNDE nesse esforço e, até mesmo, utilizar mecanismos excepcionais ... (citado em Castro, 1985, p. 37).

Apesar da emissão de nítidos sinais por parte do Governo que reduziam a incerteza futura e da existência de mecanismos de estímulo, por vezes, esses movimentos não eram suficientes para provocar decisões relevantes. Então, o Governo buscava persuadir diretamente as empresas. Por exemplo, na área dos aços não planados, Velloso disse, à época, que "quando o Consider levou ao C.D.E. a lista de novos projetos, vimos que essa lista era incapaz de dar auto-suficiência ao Brasil. Então, até por proposta minha, o Consider teve de voltar às empresas para perguntar por que elas não executavam projetos maiores" (citado em Castro, 1985, p. 37). No caso do alumínio, Velloso no ano de 1976 afirmou: "estamos voltando a conversar com o Ermírio, com a Alcoa, com a Alcan para ver se elas não vão além das expansões já programadas. E assim, em muitos setores, nós estamos tendo que provocar as empresas para viabilizar alguns projetos. É o caso do papel e celulose" (citado em Castro, 1985, p. 37-8).

Além das mensagens desenvolvimentistas enviadas por Reis Velloso, os outros dois personagens-chave, Geisel e Simonsen também sinalizavam posi- 
tivamente à economia. Contudo pode-se depreender da tese defendida pelos críticos da política econômica do período 1974-79 que Geisel e Reis Velloso emitiam sinais desenvolvimentistas aos agentes privados e Simonsen, por outro lado, teria criado algum temor empresarial de que haveria a implementação de métodos recessivos antiiflacionários. Entretanto pode-se afirmar que tanto o Presidente quanto os titulares da Fazenda e do Planejamento faziam declarações públicas e tomavam decisões plenamente sintonizados entre si e com o objetivo governamental - como é mostrado a seguir.

Nem o Ministério da Fazenda nem o Banco Central sinalizavam aos agentes a possibilidade da aplicação de métodos recessivos. O Globo de 17-031974 anunciava: "Simonsen quer manter a taxa de crescimento anual de 10\%". Essa posição externada não somente pelo ministro da Fazenda, mas pelo conjunto do Governo, foi fundamental. Segundo Velloso, "se, em agosto de 1974, se tivesse estabelecido para 1975 uma meta de expansão do PIB de, digamos, 4 a $6 \%$, o desânimo teria sido total. Essa taxa de crescimento mais baixa teria ocorrido, não em 1975, mas já em 1974" (citado em Castro, 1985, p. 39). Nas palavras do ministro do Planejamento duas idéias estão cristalinas: (i)-as metas fixadas pelo Governo e as declarações dos dirigentes eram prontamente absorvidas pela iniciativa privada na forma de decisões de investimento e, portanto, (ii)-era necessário sinalizar positivamente à economia para obter resultados satisfatórios.

Nessa mesma data, 17-03-1974, O Globo também noticiou: "Paulo Lira [presidente do Bacen] defende endividamento externo para desenvolver o País". Nessa matéria, o presidente do Banco Central disse:

Conviver com a inflação [...] não é aceitá-la passivamente. Não se deve confundir convivência com conivência. Mas antes, e de dimensão muito mais profunda, trata-se da opçâo deliberada de estimular o crescimento da produçâo. [...] O fundamental é fornecer crédito adequado, em termos reais, às atividades econômicas, de forma continuada e sem sobressaltos para propiciar as transformaçôes da estrutura produtiva.

Em sintonia com os sinais emitidos pelo presidente Bacen, Simonsen declarou a O Globo de 20-12-1975: "parece-me que as medidas de aperto devem ser tomadas quando se revelam necessárias e não por mero sadismo. Enquanto um país tem fôlego para crescer sem inibições, não há porque abafar. Afinal, o objetivo central de uma economia em desenvolvimento é a maximização dentro do possível da taxa de crescimento".

Assim, tanto o Ministro da Fazenda quanto o Presidente do Banco Central não sugeriam a utilização de métodos antiinflacionários recessivos em detrimento da opção de crescimento. Não sinalizavam também com a necessi- 
dade da economia se ajustar às novas condições internacionais praticando políticas econômicas contracionistas. Essas afirmações, entretanto, não autorizam a conclusão de que o Governo não estava disposto a combater as expectativas inflacionárias. Em matéria editada por O Globo de 20-03-1974 cuja manchete era As grandes metas do Governo Geisel, o Presidente da República explicitou o seu compromisso com a meta de manutenção do crescimento e apresentou suas decisões de cunho antiinflacionário. ${ }^{8}$ Em relação ao combate à inflação, o documento assinado pelo Presidente, reproduzido nessa matéria do periódico, dizia:

Vários preços internos, como os dos derivados de petróleo sofrerão realinhamentos em conseqüência da crise internacional de matérias-primas. Mas esses reajustes corretivos não devem servir de pretexto a retomada de expectativas inflacionárias irresponsáveis e corrosivas. [...] Às fortes influências inflacionárias que ora chegam do exterior responderemos com redobrada vigilância na contenção da inflação mantendo os mecanismos de controle preços e salários ainda indispensáveis à contenção das pressões altistas [...] de modo que nunca se penalizem os esforços válidos de melhoria da produtividade nem estabeleçam privilégios ou disparidades entre produtores. A par disso, as medidas monetárias e fiscais cabíveis deverão ser tomadas para proteção do consumidor em geral e das iniciativas empresariais, das quais depende o próprio desenvolvimento do País.

Pode-se concluir, portanto, que os sinais emitidos pelos dirigentes governamentais eram bastante nítidos e apontavam na direção do crescimento e do combate à inflação explosiva. Assim, o Governo reduzia a incerteza empresarial em relação ao futuro e, conseqüentemente, estimulava a tomada de decisões relevantes. Ademais, os sinais governamentais não eram contaminados por eventuais ruídos recessivos transmitidos pelo Ministério da $\mathrm{Fa}$ zenda ou pelo Banco Central. Ainda mais, quando os sinais e os mecanismos de estímulo não eram suficientes, persuadia-se diretamente o empresariado para garantir a sua adesão a projetos mais vultosos. Por conseguinte, conclui-se que a política econômica do período Simonsen-Velloso emitiu claros sinais aos empresários e estimulou-os a agir no mesmo sentido das ações governamentais.

\section{Conclusões}

Foi apresentada nos trabalhos de Coutinho (1981), Bresser Pereira (1983), Carneiro (1990) e CAMPOS (1998), uma tese crítica à política econômica implementada durante o Governo Geisel. Sem utilizar nenhum método explí-

\footnotetext{
${ }^{8}$ A Confederação Nacional da Indústria em reunião dia 26-03-1974 elogiou as metas governamentais, ver O Globo de 28-03-1974
} 
cito para avaliação das ações econômicas àquele período, esses autores avaliaram que existiam dois pólos opostos no interior do Governo. Enquanto Reis Velloso desejaria impulsionar a economia rumo ao crescimento, Simonsen almejaria o fim da inflação com a utilização de métodos recessivos. Em decorrência, consideraram que a política econômica do período Simonsen-Velloso enfraqueceu-se e que possuía objetivos conflitantes.

Com base nas idéias de Keynes e de alguns de seus seguidores, foi definido um método de avaliação da eficiência de políticas econômicas. Uma política econômica eficiente seria aquela que atende a três requisitos. Primeiro, possui um objetivo prioritário, segundo, não utiliza persistentemente seus instrumentos de forma conflitante e, terceiro, emite nítidos sinais aos agentes privados a fim de estimulá-los a agir ombro a ombro com Governo. A política econômica desenvolvida pela gestão Simonsen-Velloso foi avaliada à luz desse método.

A política econômica do período 1974-79 tinha um único objetivo prioritário: crescer sem acelerar a taxa de inflação. Foi demonstrado que Simonsen, um simpatizante das idéias monetaristas, concordava com esse objetivo. O Ministro da Fazenda desejava combater as tendências de aceleração da taxa de inflação e não eliminá-la integralmente com métodos recessivos. $\mathrm{O}$ monetarismo considerava à época que em uma economia indexada e que não registrava taxas crescentes do nível de preços não se verificaria os efeitos perversos da inflação. Nesse sentido, não existiam metas conflitantes, tais como crescimento e o fim da inflação. Em suma, as políticas monetária e fiscal naqueles anos perseguiam um único objetivo, logo, de acordo com o primeiro requisito (do método de avaliação estabelecido), podem ser consideradas eficientes.

Os instrumentos da política econômica do período 1974-79 foram minimamente utilizados de forma contraditória/conflitante. Em alguns trimestres isolados, os instrumentos de política monetária e fiscal atuaram em sentidos opostos. Tal utilização-contraditória pode ser atribuída ao grau de flexibilidade dos instrumentos. Em geral, as ferramentas fiscais possuem um timing diferente dos instrumentos monetários - o que caracterizaria efetivamente uma utilização contraditória seria uma caminhada persistente em sentidos opostos. Por exemplo, na Alemanha, durante todo o ano de 1981, a política implementada pelo Bundesbank foi restritiva, enquanto o Governo desenvolveu um política agressiva de gastos. O Bundesbank objetivava eliminar a inflação e o Governo buscava reduzir o desemprego. Foi verificado que, no período SimonsenVelloso, não existiu nenhuma situação semelhante àquela experimentada pela economia alemã no ano de 1981. Portanto, em relação ao segundo requisito, a política econômica de 1974-79 foi eficiente. Contudo cabe ser destacado que no último ano de Governo, em particular no último trimestre, as políticas não foram integralmente consistentes com o objetivo. A despeito dos sintomas de 
aceleração da inflação, as políticas fiscal e monetária foram ainda expansionistas.

A política econômica durante o período Simonsen-Velloso emitiu sinais que estimularam os empresários a agir na direção apontada pelo Governo. Objetivava-se fazer um crescimento-qualitativo da economia e, simultaneamente, impedir que a inflação se descontrolasse explosivamente. Quando os sinais e mecanismos de incentivos não eram totalmente eficazes, os dirigentes do Governo tentavam diretamente convencer os empresários dos setores prioritários para liderar o crescimento a se engajar em projetos mais volumosos. Simonsen, Reis Velloso e Geisel faziam declarações públicas e tomavam decisões que não transmitiam qualquer ambigüidade aos agentes privados. Cabe destacar que o Ministério da Fazenda e o Banco Central não contaminavam os sinais governamentais com ruídos recessivos. Portanto, no que diz respeito ao terceiro quesito de avaliação, a política econômica do período 1974-1979 foi eficiente.

Concluiu-se, finalmente, que durante a gestão de Simonsen-Velloso, a política econômica não foi ineficiente. Segundo os três requisitos do método de avaliação estabelecido, as ações monetárias e fiscais mostraram-se coerentes entre si, consistentes com a meta prioritária de Governo e estimuladoras de decisões de investimento. Portanto não há qualquer fundamento sólido que justifique a existência de teses críticas à gestão econômica do período 197479. A política econômica daqueles anos desencadeou apenas movimentos de stop-and-go, como foi observado na seção 4, mas, como foi destacado na seção 2 , tal política não é necessariamente ineficiente.

\section{Referências bibliográficas}

BRESSER PEREIRA, L.C.(1983). Auge e declínio nos anos setenta. Revista de Economia Politica, vol.3, n.2, abr-jun.

CAMPOS, R. (1998). Mario Simonsen, um matemático humanista, Revista Brasileira de Economia, vol.52, número especial.

CAIRNCROSS, A.(1992). Economía y Política Económica. México: Fondo de Cultura Económica.

CARNEIRO, D.D.(1990). Crise e Esperança. IN: ABREU, M.P.(org.), A Ordem do Progresso. Rio de Janeiro: Editora Campus

CASTRO, A.B.(1985). Ajustamento X Transformação - a economia brasileira de 1974 a 1978. IN: Castro, A.B. \& Pires de Souza, F.E., A Economia Brasileira em Marcha Forçada. Rio de Janeiro: Paz e Terra.

COUTINHO, L.(1981). Inflexões e crise da política econômica: 1974-1980. Revista de Economia Política, vol.1, n.1, jan-mar.

FRIEDMAN, M.(1968). The Role of Monetary Policy, American Economic Review, March.

- (1974). Monetary Correction. IN: Essays on Inflation and Indexation. 
Whashington: Domestic Affairs Studies.

MOGGRIDGE, D.(1993). Keynes. London: MacMillan.

O GLOBO. (foram utilizados diversos exemplares que são citados com suas datas completas: dia-mês-ano).

SIMONSEN, M.H.(1977). Politica Monetária, Reservas Cambiais e Exportações: desempenho em 1976 e diretrizes para 1977. Palestra proferida no Sheraton Hotel aos empresários. Rio de Janeiro, 28 de Janeiro.

(1976a). Aspectos Atuais do Desenvolvimento Brasileiro. Palestra proferida à Comissão de Economia da Câmara dos Deputados. Brasília, 29 de abril.

-(1976b). Aspectos Atuais da Conjuntura Brasileira. Palestra proferida na Escola Superior de Guerra. Rio de janeiro, 8 de julho.

TINBERGEN, J.(1952). On the Theory of Economic Policy. Amsterdam: NorthHolland Publishing Company.

TOBIN, J.(1987). Policies for Porsperity. Sussex: Wheatsheaaf Books.

VELLOSO, J.P.R. (1998). O Governo Geisel: estratégia de desenvolvimento e coordenação da política econômica, Revista Brasileira de Economia, vol.52, número especial.

(1986). O último trem para Paris. Rio de Janeiro: Nova Fronteira. 